\section{IT'S MY LIFE: INFLUENCES ON ADVANCE CARE PLANNING CONVERSATIONS}

10.1136/bmjspcare-2011-000053.43
- 2 withdrew after reading the information sheet.

- 1 retrospectively withdrew consent.

- 1 died before participation.

- 1 did not meet the sample criteria.

The findings indicate participants:

(a) Can feel processed through an end of life check list to make decisions where they are given the decisions and then asked to think rather than think and decide.

(b) Do not always discuss issues with those closest to them because of a desire to protect them.

(c) Are not always willing to make advance care planning decisions not because they are unaware of their illness but because they do not feel resilient to face the emotional impact of their choices as well as being within the advance care planning process of; (1) consideration of wishes and preferences, (2) discussion, (3) discussion and decision making, (4) decision making and documentation, (5) communication and implementation.

(d) Are willing to discuss end of life wishes and preferences when conversations are empathetic, at their pace and as part of an ongoing process.

Conclusion Health care professionals should value the consideration and discussion part of advance care planning as the vehicle and support mechanism for decision making outcomes. A reductionist, tick box approach to advance care planning can enable participants to feel processed through rather than participating in advance care planning discussions.

S Russell Hospice of St Francis, Hertfordshire, UK

As part of a doctoral research study 20 hospice patients responded to an invitation to participate in a video interview to discuss their influences on discussing end of life wishes and preferences. 15 participants were interviewed. 